\title{
Land Use Land Cover Mapping with Change Detection: A Spatio- Temporal Analysis of Ambo Woreda, Ethiopia from 2000 to 2020
}

\author{
Riyaz Khan N. H. \\ ${ }^{I}$ Department of Cadastral Surveying and Geomatics Engineering, Ambo University, Ethiopia.
}

${ }^{a)}$ Corresponding Author: civilianhrk@gmail.com

\begin{abstract}
Received : 3/11/2021
Acceptance : $27 / 11 / 2021$

Available online: $31 / 12 / 2021$
\end{abstract}

\begin{abstract}
The main aim of this present study is to identify and detect the land use, land cover changes occurred in the Ambo Woreda of West Shewa Zone in Ethiopia and to integrate the Remote Sensing and GIS data for analyzing and evaluating the changes in land-use of study area. Based on remotely sensed data, the Land Use Land Cover (LULC) maps and field records have been considered for investigation. Landsat7 ETM+ image of 2000 and Sentinel 2A image of 2020 are the two remotely sensed images of study area used in this study. The supervised classification based on maximum likelihood classifier in ArcGIS 10.3 has been used to identify the five major categories of LULC. The observation on the period of twenty years reveals that the agricultural land and built-up areas have stretched rapidly to the adjacent fallow lands. Also, there is significant loss in Hilly Vegetation due to settlements and industrial expansion in the fastest growing region of the Oromia Zone.
\end{abstract}

Keywords. Land Use Land Cover, Change Detection, Sentinel - 2A, Supervised Classification, Ambo.

\section{INTRODUCTION}

For a human being to survive on earth, land is one of the important natural resource next to water. Land use is explained as how man is utilizing the land whereas land cover is the vegetation spread over the land. LC data shows how much of an area is covered by natural phenomena but land use data shows how people utilize the landscape [1]. Drastic changes in land use and land cover (LULC) have been seen since the twentieth century and those traceable changes resulted in a complex land use structure [2]. Due to the increase in population and the flow of people from rural to urban areas, major towns and cities of the world have experienced rapid urban growth. Various driving factors like population pressure and development makes the LULC change dynamics non-uniform throughout the world [3].

"Like many other developing countries, Ethiopia has been experiencing environmental degradation problems including LULC conversion, soil erosion, loss of forest and other vegetation covers and water resource degradation"[4]. Studies on the Ethiopian highlands showed that the expansion of cultivated land increased through time at the expense of natural forest and also claimed that deforestation has been reduced in the recent times due to the plantation activities on degraded hillsides which led to improvement in vegetation cover [5]. Farmland, settlements and degraded lands were expanding considerably while grasslands and forest areas have been diminished driven by economic factors and policy issues [6]. Ethiopian highlands are prone to heavy degradation and frequently affected by drought and famine. More and more marginal lands are being used for agriculture due to the population growth in the highland areas [7].

Besides, the reliability on woody biomass for fuel, the expansion of agricultural activities at the expense of vegetation cover and demand for wood for construction activities are the two main factors led to the uncontrolled land cover change and deforestation in Ethiopia [8]. Analysis of LULC changes have significant roles in the understanding of earth-atmosphere, forest fragmentation and future management plans. Hence, LULC changes should be quantified and investigated. However, spatial pattern, extent and rates of such land cover changes have never been quantified and analyzed in the study area using the high resolution satellite imagery [9].

In recent times, multispectral and multi-temporal satellite data with medium to high resolutions, have emerged as an important tool for estimating various aspects like vegetation cover, forest degradation and urban expansion [5], [10]. Remote Sensing (RS) and Geographical Information Systems (GIS) has been used as a primary tool for identification, analysis and quantification of LULC changes [10]-[13]. High resolution satellite data like Sentinel -2A data can be used for preparing land cover maps and accurate results will be yielded in change detection analysis [14]. However, medium resolution data such as the Thematic Mapper (TM), Enhanced Thematic Mapper + (ETM+) and Operational Land Imager (OLI) have been used extensively in the studies for LULC change detection analysis due to the limited availability of Sentinel datasets [3], [15][18].

Despite, being the epicentre of Oromia, Ambo town lacks attention of scientific information on land use and land cover change. These kinds of analyses are very essential for the future planning and developments. The present research study was carried out with the following objectives (a) to evaluate land use and land cover change from 2000 to 2020 and (b) to perform change detection analysis to understand how various land use land cover types changed over this period. 


\section{MATERIALS AND METHODS}

\section{- Study Area}

The study was conducted in the Ambo Woreda, Ethiopia. The study area map is shown in Figure 1, which is a spa town located in the West Shewa Zone of the Oromia Region, at $125 \mathrm{kms}$ west of Addis Ababa. The area lies within $8^{\circ} 45^{\prime}-9^{\circ} 25^{\prime} \mathrm{N}$ latitude to $37^{\circ} 35^{\prime}-38^{\circ} 00^{\prime}$ E longitude at an altitude of 2101 metres above sea level. It covers an area of 95966.2 hectares. It experiences subtropical highland climate.

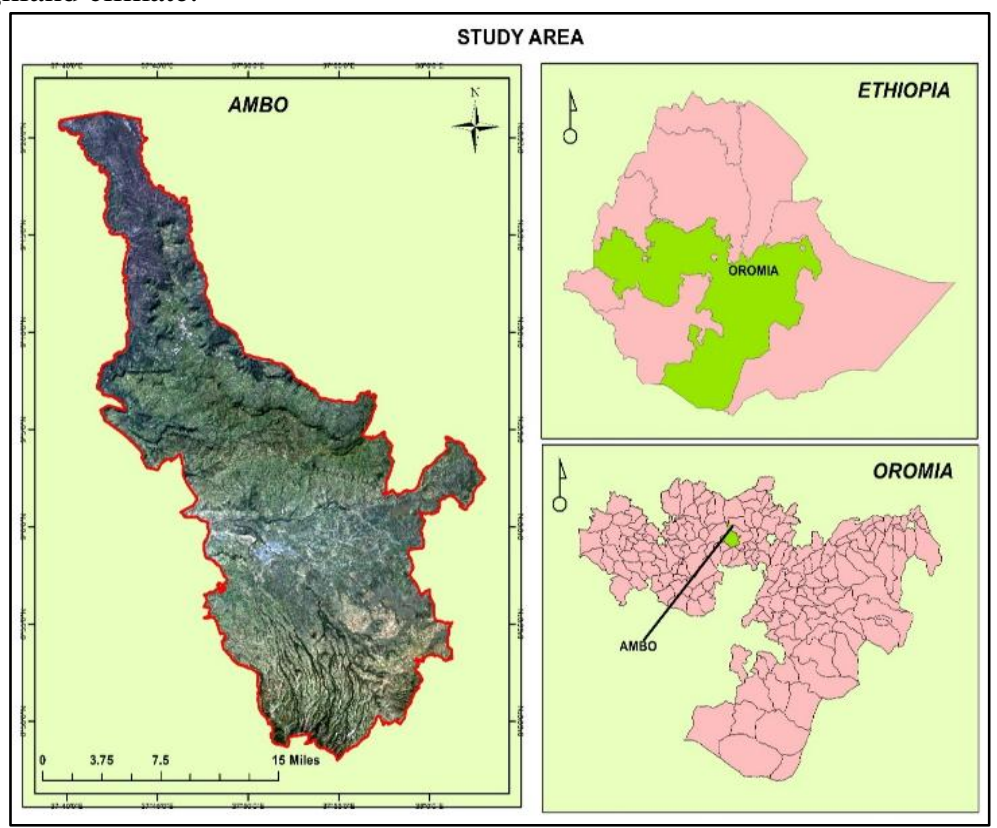

FIGURE 1. Study Area Map.

\section{- Data Sources}

Two period of satellite images were used to conduct this study as shown in Table 1. Digital map on shapefile of scale of 1:25000 from DIVA GIS were used as supporting spatial data for delineating the study area boundary. In addition, to that Global Positioning System (GPS) points marked during fieldwork, were used in the collection of Ground Control Points (GCP) as the support for the classification. Nearly 110 sample-training sites have been used in each year (2000 and 2020) from ancillary data like high-resolution Google Earth Imagery.

The Landsat7 ETM+ data, which are acquired on the Worldwide Reference System-2 path/row system dated on 26.11.2000 has been used in this study. It is a Level-1TP product which provides radiometric and geodetic accuracy. The Sentinel $-2 \mathrm{~A}$ data acquired on 12.11.2020 is another data used in the current study for extracting LULC information. It is a Level-1C product which is geometrically and radiometrically corrected. The Landsat satellite has the revisit period of 16 days where as the sentinel series has the revisit period of 5 days which makes it more useful for choosing from the cloud free day. The cloud cover of Landsat and Sentinel images used in this study are $0 \%$ and $0.12 \%$ respectively. Both of these images have been downloaded from the United States Geological Survey (USGS) Earth Explorer archives.

TABLE 1. Data Used.

\begin{tabular}{ccccc}
\hline Satellite & Sensor & Acquisition Date & Resolution(m) & Source \\
\hline 1. Landsat7 & ETM+ & 26/NOV/2000 & $30 * 30$ & USGS \\
2. Sentinel & $2 \mathrm{~A}$ & $12 / \mathrm{NOV} / 2020$ & $10 * 10$ & USGS \\
\hline
\end{tabular}

\section{- $\quad$ Image Pre-Processing}

Image pre-processing is an initial step which will help to remove the distortions and extract valuable information from the satellite image. For the present study, Toposheet of the study area has been downloaded from the US Army maps website due to the limited availability for the region and it has been used as the base map for geometric correction after geo-referencing. For Landsat7 ETM+ image, geometric correction by the method of Image Warping and Radiometric Correction have been done using the ENVI 5.3. And for the Sentinel 2A image, Rayleigh correction has been applied by using SNAP 7.0 (Sentinel Application Platform). Both of these images have been registered to the Adindan UTM Zone 37N projection. The layer stack option was used to generate the composite images. Extraction of the Area of Interest was (AOI) was done through the subset option. 
- Image Classification

The process of image classification aims to classify all the pixels in the processed satellite images to the desired land use and land cover categories. For the current study, Supervised Classification based on Maximum Likelihood Classifier has been selected for classifying pixels. To facilitate supervised classification, training samples were given using the signatures exhibited by each land use and land cover category. A total of five land use classes were established, by Anderson's Level 1 (1972) classification based on information from local communities, properties of Landsat and Sentinel images, data like Google Earth and field observation as shown in Table 2. LULC map is prepared with the help of ArcGIS 10.3 and ENVI 5.3.

TABLE 2. LULC Types.

\begin{tabular}{ccc}
\hline No. & LULC Type & Description \\
\hline 1 & Hilly Vegetation & $\begin{array}{r}\text { Forest, Grasslands and plantations found in } \\
\text { the elevated hilly places. }\end{array}$ \\
2 & Agricultural Land & $\begin{array}{r}\text { Areas used for crop production and scattered settlements } \\
\text { associated with agricultural land. }\end{array}$ \\
3 & Fallow Land & $\begin{array}{r}\text { Agricultural land which are left without cultivation } \\
\text { for a period of time. }\end{array}$ \\
4 & Barren Land & $\begin{array}{r}\text { Areas of sparse vegetation cover including cultivated lands without } \\
\text { crops and barren rock or sand. }\end{array}$ \\
5 & Built-up & Areas occupied by residential houses, buildings and industries. \\
\hline
\end{tabular}

\section{- Accuracy Assessment}

To determine the accuracy of the classification, the number of reference pixels is an important factor. An equalized stratified random sampling approach was used to assess the accuracy of each of the two land cover classifications. The overall accuracy and a KAPPA analysis were used to perform classification accuracy assessment based on error matrix analysis.

Accuracy assessment was performed for 2000 and 2020 LULC maps. Based on the stratified random sampling method, a total of 110 pixels were randomly selected for each year. For the 2000 LULC map, the result shows an overall accuracy of $80 \%$ and a kappa index of agreement of 0.73 as shown in Table 3. In terms of User's accuracy, all classes were over $80 \%$ except fallow land and barren land which were $78 \%$ and $70 \%$ respectively. In terms of Producer's accuracy, all classes were over $85 \%$ except barren and agriculture lands.

For the 2020 LULC map, the result shows an accuracy of $84.54 \%$ and a kappa index of agreement of 0.79 as shown in Table 4 , In terms of User's accuracy, all the classes were over $83 \%$ except barren land which was $75 \%$. In terms of Producer's accuracy, built-up class was $100 \%$, whereas hilly vegetation and agricultural land were over $85 \%$. And the fallow land showed over $77 \%$.

The confusion error matrix and Kappa statistics used for the classification accuracy of 2000 and 2020 LULC maps are presented in Tables 3 and 4. The kappa statistics showed a strong agreement for the years 2000 and 2020.

TABLE 3. Accuracy Assessment Results for the LULC Map of 2000.

\begin{tabular}{|c|c|c|c|c|c|c|c|c|}
\hline & HV & FL & $\mathbf{U L}$ & BL & $\mathbf{A L}$ & Total & User's Accuracy (\%) & Kappa \\
\hline $\mathrm{HV}$ & 27 & 2 & 0 & 1 & 3 & 33 & 81.18 & 0 \\
\hline FL & 2 & 25 & 0 & 1 & 4 & 32 & 78.12 & 0 \\
\hline UL & 0 & 0 & 9 & 1 & 0 & 10 & 90.00 & 0 \\
\hline $\mathrm{BL}$ & 1 & 1 & 0 & 7 & 1 & 10 & 70.00 & 0 \\
\hline $\mathrm{AL}$ & 1 & 1 & 1 & 2 & 20 & 25 & 80.00 & 0 \\
\hline Total & 31 & 29 & 10 & 12 & 28 & 110 & 0 & 0 \\
\hline Producer's Accuracy (\%) & 87.10 & 86.20 & 90.00 & 58.34 & 71.42 & 0 & 80 & 0 \\
\hline Kappa & 0 & 0 & 0 & 0 & 0 & 0 & 0 & 0.73 \\
\hline \multicolumn{9}{|c|}{ TABLE 4. Accuracy Assessment Results for the LULC Map of 2020.} \\
\hline & HV & FL & UL & BL & AL & Total & User's Accuracy (\%) & Kappa \\
\hline $\mathrm{HV}$ & 25 & 1 & 0 & 2 & 2 & 30 & 83.34 & 0 \\
\hline FL & 1 & 14 & 0 & 1 & 0 & 16 & 87.50 & 0 \\
\hline $\mathrm{UL}$ & 0 & 0 & 12 & 0 & 1 & 13 & 92.30 & 0 \\
\hline $\mathrm{BL}$ & 0 & 1 & 0 & 9 & 2 & 12 & 75.00 & 0 \\
\hline $\mathrm{AL}$ & 1 & 2 & 0 & 3 & 33 & 39 & 84.61 & 0 \\
\hline Total & 27 & 18 & 12 & 15 & 38 & 110 & 0 & 0 \\
\hline Producer's Accuracy (\%) & 92.59 & 77.78 & 100 & 60.00 & 86.84 & 0 & 84.54 & 0 \\
\hline Kappa & 0 & 0 & 0 & 0 & 0 & 0 & 0 & 0.79 \\
\hline
\end{tabular}

${ }^{*} \mathrm{HV}$ - hilly vegetation, FL - fallow land, UL - built-up, BL - barren land, AL - agricultural land

\section{RESULTS AND DISCUSSION}


The classification results provided a great detail of the key LULC features of the Ambo town for the selected period. Comprehensive dataset with tabulations and area calculations can provide insight into the defined classes and changes across the landscape and this has to be shown graphically for better representation.

Land use maps were prepared for the year 2000 and 2020. After, obtaining supervised classification Accuracy Assessment was done by comparing classified image with Ground Control Points taken on field survey and by using Google Earth. Data interpretation involves the comparison of classes during the term of 20 years. The figures 2 and 3 show the classified images of Ambo Woreda showing different LULC classes for the year 2000 and 2020.

Massive LULC changes can be noticed during this period. Agricultural Land, the dominant land use type of the area has expanded immensely and increased. It covers around 61.5\% (37942.92 hectares) of the land in 2020 as compared to the $39.5 \%$ (59009.06 hectares) in 2000. This was the outcome of the Ethiopia's Agricultural Sector Policy and Investment Framework (PIF) of 2010 which has the main objective of achieving a sustainable increase in agricultural productivity and production. Similarly, Built-up and Barren Land areas increased from 2000 to 2020 . The proportion of built-up areas in 2000 and 2020 were $0.58 \%$ (558.9 hectares) and 7.64 (7339.7 hectares) of the total area respectively. The barren land covered $7.67 \%$ ( 7357.95 hectares) of the area in 2000 whereas it covered up to $12.15 \%$ (11666.69 hectares) in 2020.

In 2000, Hilly Vegetation and Fallow Land were the second most major LULC types accounting for $29.49 \%$ (28305.18 hectares) and $22.71 \%$ (21796.83 hectares) of the total area respectively. Conversely, to the preceding period of 2000 Hilly Vegetation and Fallow Land showed a decrement in the year of 2020 with the coverage of 13.14\% (12611.23 hectares) and $5.56 \%$ (5339.8 hectares).

The LULC showed spatio-temporal dynamics (Table 5, Figures 4 and 5) throughout the study period (2000-2020). Agricultural land showed highest rate of change followed by Fallow land and Hilly vegetation. Both fallow land and hilly vegetation showed a declining trend; whereas agricultural land, barren land and built-up showed an increasing trend. There is a huge increment in areas of agricultural land coverage up to (21066.14 ha). Next type of class which showed increment in coverage is Built-up and its coverage risen up to (6780.8 ha) in this period. There is a slight increment in barren land with the difference in coverage of (4308.74 ha). On the other hand, Hilly vegetation and fallow land have fallen by an aerial coverage of (15693.95 ha) and (16457.03 ha) respectively.

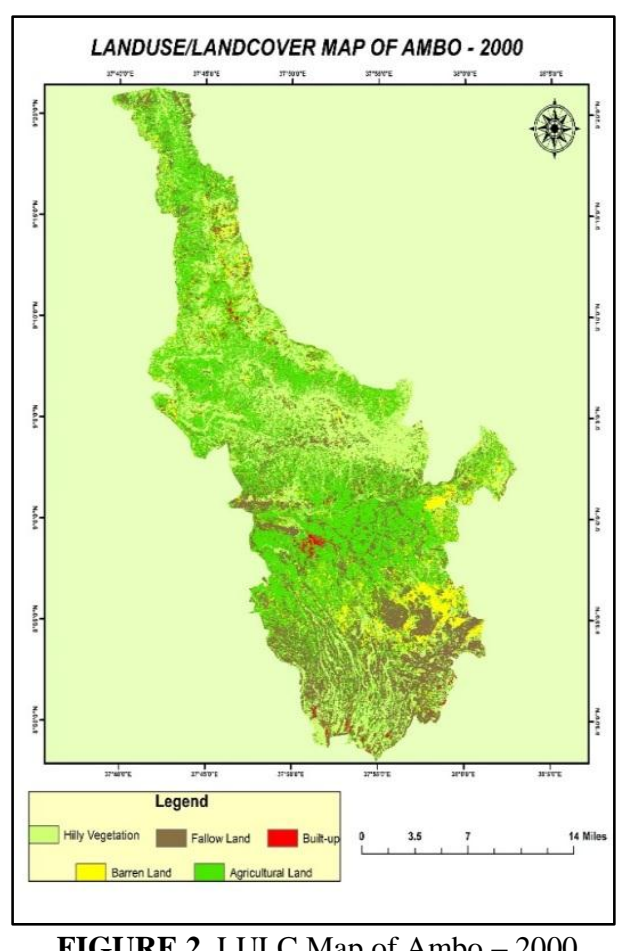

FIGURE 2. LULC Map of Ambo - 2000

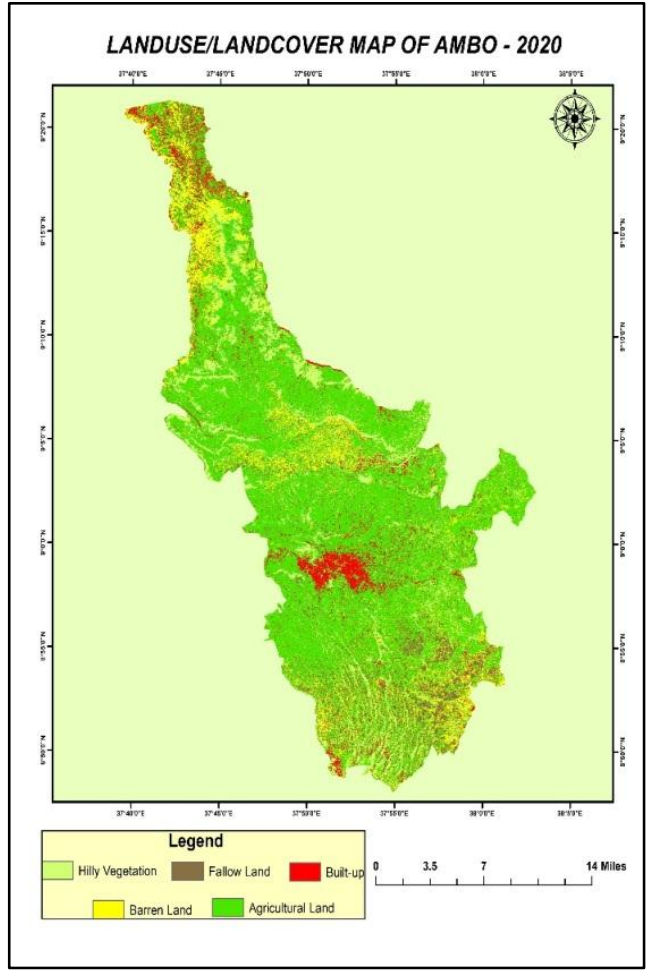

FIGURE 3. LULC Map of Ambo - 2020.

TABLE 5. LULC area coverage, status and changes. 


\begin{tabular}{cccccc}
\hline \multicolumn{2}{c}{$\mathbf{2 0 0 0}$} & \multicolumn{2}{c}{$\mathbf{2 0 2 0}$} & \\
\hline CLASS & Area (in Ha) & Area (in \%) & Area (in Ha) & Area (in \%) & Change (in \%) \\
\hline Hilly Vegetation & 28305.18 & 29.49630572 & 12611.23 & 13.14128642 & -16.3550193 \\
Agricultural Land & 37942.92 & 39.53961671 & 59009.06 & 61.48924083 & 21.94962412 \\
Fallow Land & 21796.83 & 22.71407429 & 5339.8 & 5.564234512 & -17.14983978 \\
Barren Land & 7357.95 & 7.667583907 & 11666.69 & 12.15704692 & 4.489463012 \\
Built-up & 558.9 & 0.582419376 & 7339.7 & 7.648191327 & 7.065771951 \\
\hline
\end{tabular}

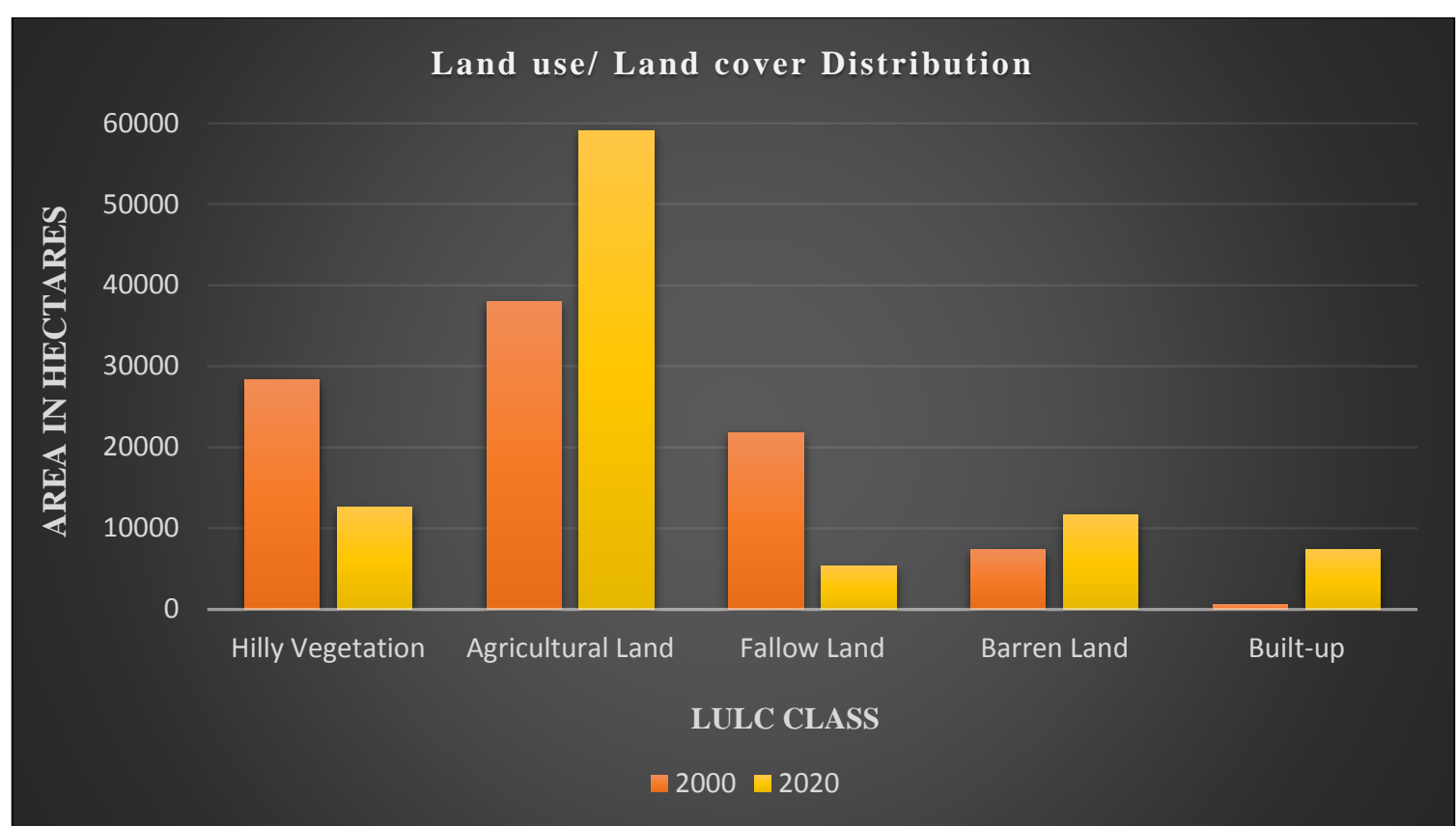

FIGURE 4. LULC Distribution.

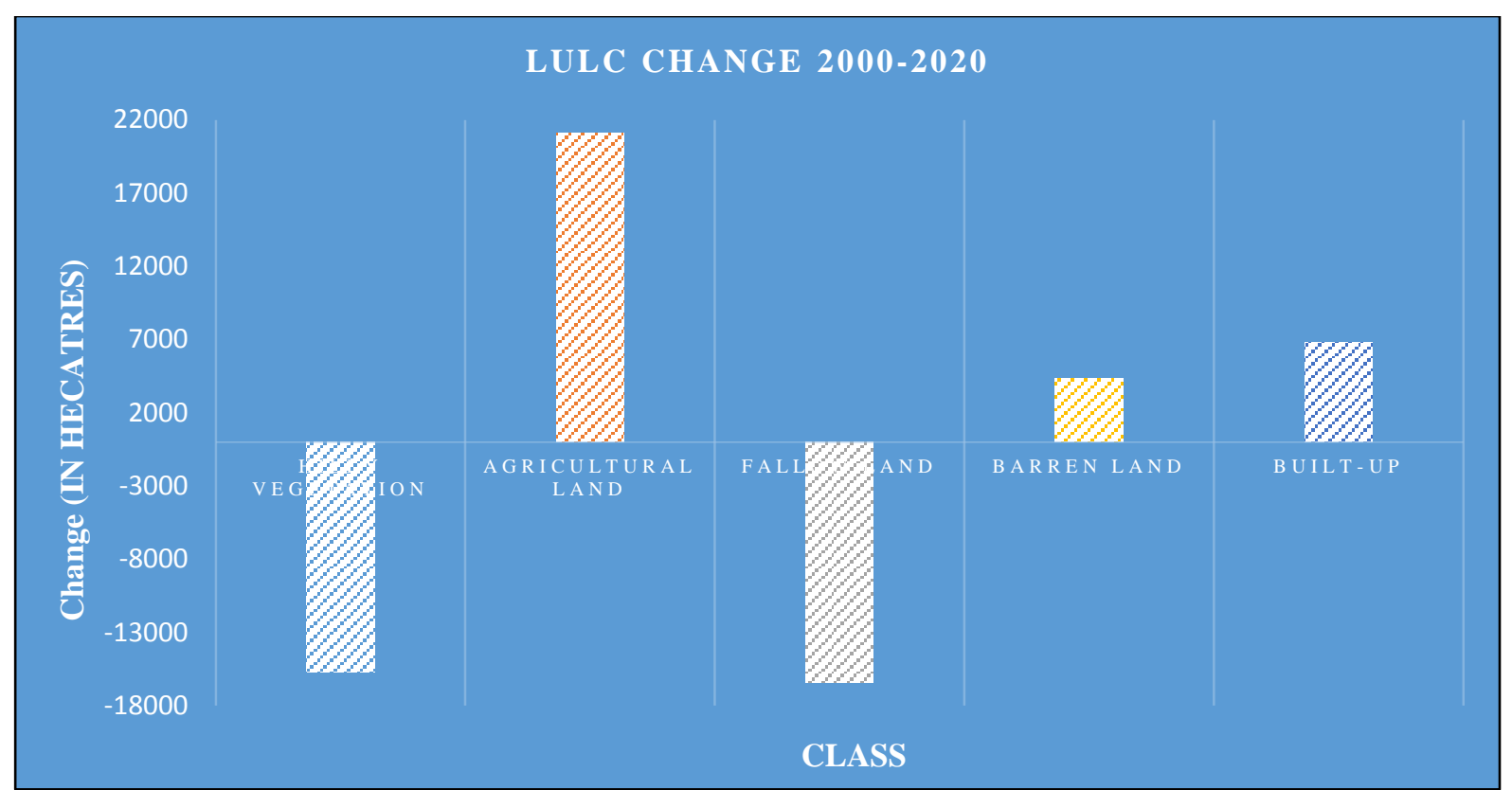

Figure 5. LULC Change

\section{CONCLUSION}

The present work on the spatio-temporal analysis of LULC types in the Ambo Woreda in West Shewa Zone of Ethiopia has revealed that there were significant LULC changes in the area during 2000-2020 periods. The proportional changes in the area were found out for the total LULC types in two different periods. The multi-temporal analysis of satellite image data clearly showed that hilly vegetation and fallow lands have decreased; in the contrary agricultural land, barren land and built- 
up areas have showed an expansion between 2000 and 2020 years. About $21 \%$ of the agricultural land has increased, it is due to the national agricultural policy of Ethiopia. Based on field observation and discussion with local communities, the major causes for the changes of this LULC types are through settlements of people shifting from rural areas in to the ambo town, industrial development, overgrazing and increased agricultural production. So, appropriate measures should be taken to promote the development of this area to reduce its negative impact on the society and environment. And also, this study recommends the use of high-resolution Sentinel-2A imagery for extracting land use information with greater accuracy. Furthermore, RS and GIS based study on LULC changes are vital for urban land use planning. This kind of analytic study would be helpful for further research and planning of land use of the Ambo Woreda.

\section{REFERENCES}

[1] Y. Suresh and K. B. Bindu, "An Analysis of Land use / Land cover in Kadalundi River Basin using Remote Sensing and GIS," vol. 6, no. 2, pp. 1442-1449, 2015.

[2] S. Tikader, "Spatio-temporal changing pattern of LULC: An Overview," vol. 7, no. 2, pp. 235-244, 2016.

[3] M. I. Sarwar, M. Billa, and A. Paul, "Urban land use change analysis using RS and GIS in Sulakbahar ward in Chittagong city, Bangladesh,” Int. J. Geomatics Geosci., vol. 7, no. 1, pp. 1-10, 2016.

[4] B. Gessesse and W. Bewket, "Drivers and Implications of Land Use and Land Cover Change in the Central Highlands of Ethiopia: Evidence from Remote Sensing and Socio-demographic Data Integration,” Ethiop. J. Soc. Sci. Humanit., 2014.

[5] M. L. Berihun et al., "Exploring land use/land cover changes, drivers and their implications in contrasting agro-ecological environments of Ethiopia," Land use policy, vol. 87, no. March, p. 104052, 2019, doi: 10.1016/j.landusepol.2019.104052.

[6] E. E. Hassen and M. Assen, "Land use/cover dynamics and its drivers in Gelda catchment, Lake Tana watershed, Ethiopia," Environ. Syst. Res., vol. 6, no. 1, 2018, doi: 10.1186/s40068-017-0081-x.

[7] M. Kidane, A. Bezie, N. Kesete, and T. Tolessa, "The impact of land use and land cover (LULC) dynamics on soil erosion and sediment yield in Ethiopia," Heliyon, vol. 5, no. 12, p. e02981, 2019, doi: 10.1016/j.heliyon.2019.e02981.

[8] A. Mekonnen and A. Damte, "Private Trees as Household Assets and Determinants of Tree-Growing Behavior in Rural Ethiopia," no. December, p. 29, 2011.

[9] S. M. Herrmann, M. Brandt, K. Rasmussen, and R. Fensholt, "Accelerating land cover change in West Africa over four decades as population pressure increased," Commun. Earth Environ., vol. 1, no. 1, pp. 1-10, 2020, doi: 10.1038/s43247-020-00053-y.

[10] G. N. Vivekananda, R. Swathi, and A. V. L. N. Sujith, "Multi-temporal image analysis for LULC classification and change detection,” Eur. J. Remote Sens., vol. 54, no. sup2, pp. 189-199, 2021, doi: 10.1080/22797254.2020.1771215.

[11] M. Güler, T. Yomralioğu, and S. Reis, "Using landsat data to determine land use/land cover changes in Samsun, Turkey," Environ. Monit. Assess., vol. 127, no. 1-3, pp. 155-167, 2007, doi: 10.1007/s10661-006-9270-1.

[12] A. Debnath, J. Debnath, I. Ahmed, and N. Das Pan, "Change detection in Land use / cover of a hilly area by Remote Sensing and GIS technique : A study on Tropical forest hill range , Baramura, Tripura , Northeast India,” vol. 7, no. 3, pp. $293-309,2017$.

[13] M. W. Naikoo, M. Rihan, M. Ishtiaque, and Shahfahad, "Analyses of land use land cover (LULC) change and built-up expansion in the suburb of a metropolitan city: Spatio-temporal analysis of Delhi NCR using landsat datasets," J. Urban Manag., vol. 9, no. 3, pp. 347-359, 2020, doi: 10.1016/j.jum.2020.05.004.

[14] S. Vigneshwaran and S. V. Kumar, "Urban land cover mapping and change detection analysis using high resolution sentinel-2A data," Environ. Nat. Resour. J., vol. 17, no. 1, pp. 22-32, 2019, doi: 10.32526/ennrj.17.1.2019.03.

[15] C. A. Vishwakarma, S. Thakur, P. K. Rai, V. Kamal, and S. Mukherjee, "Changing land trajectories: A case study from india using a remote sensing based approach," Eur. J. Geogr., vol. 7, no. 2, pp. 61-71, 2016.

[16] M. Vakha, M. Nagaraju, and A. M. K. G, "Land use land cover mapping using Geo-informatics of Kodagu District , Karnataka," Int. J. Geomatics Geosci., vol. 7, no. 1, pp. 11-23, 2016.

[17] S. Parveen and S. Sarkar, "Land Use Land Cover Mapping with Change Detection : A Spatio-temporal Analysis of NCT of Delhi from 1981 to 2015," vol. 8, no. 1, pp. 41-54, 2018.

[18] A. Sikarwar and A. Chattopadhyay, "Change in land use-land cover and population dynamics: A town-level Study of Ahmedabad city sub-District of Gujarat,” Int. J. Geomatics Geosci., vol. 7, no. 2, pp. 225-234, 2016. 